\title{
Guidelines
}

\section{Convulsive status epilepticus management in adults and children: Report of the Working Group of the Polish Society of Epileptology}

\author{
J. Jędrzejczak ${ }^{a}$, M. Mazurkiewicz-Bełdzińska ${ }^{c}$, M. Szmuda ${ }^{c}$, \\ B. Majkowska-Zwolińska ${ }^{d}$, B. Steinborn ${ }^{e}$, D. Ryglewicz $^{f}$, \\ R. Owczuk ${ }^{g}$, A. Bartkowska-Śniatkowska ${ }^{h}$, E. Widera ${ }^{i}$, \\ K. Rejdak ${ }^{j}$, M. Siemiński ${ }^{k}$, E. Nagańska ${ }^{b, *}$
}

${ }^{a}$ Department of Neurology and Epileptology, Centre of Postgraduate Medical Education, Warsaw, Poland

${ }^{\mathrm{b}}$ Department of Experimental and Clinical Neuropathology, Mossakowski Medical Research Centre, Polish Academy of Sciences, Warsaw, Poland

${ }^{\mathrm{c}}$ Department of Developmental Neurology, Chair of Neurology, Medical University of Gdańsk, Poland

${ }^{\mathrm{d}}$ Centre for Epilepsy Diagnosis and Treatment, Foundation of Epileptology, Warsaw, Poland

${ }^{\text {e }}$ Department of Developmental Neurology, Poznan Univerity of Medical Sciences, Poznań, Poland

${ }^{\mathrm{f}}$ 1st Neurological Department, Institute of Psychiatry and Neurology, Warsaw, Poland

${ }^{g}$ Department of Anaesthesiology and Intensive Therapy, Medical University of Gdansk, Poland

${ }^{\mathrm{h}}$ Department of Paediatric Anaesthesiology and Intensive Therapy, Poznan University of Medical Sciences, Poznań, Poland

${ }^{\mathrm{i}}$ Clinic of Pediatrics and Neurology of Developmental Age, Medical University of Silesia, Katowice, Poland

${ }^{j}$ Department of Neurology, Medical University of Lublin, Poland

${ }^{\mathrm{k}}$ Department of Emeregency Medicine, Medical University of Gdansk, Poland

\section{A R T I C L E I N F O}

\section{Article history:}

Received 20 March 2018

Accepted 11 April 2018

Available online 13 June 2018

Keywords:

Epilepsy

Generalized status epilepticus

Guidelines

EEG

\begin{abstract}
A B S T R A C T
Introduction: The Working Group was established at the initiative of the General Board of the Polish Society of Epileptology (PSE) to develop an expert position on the treatment of convulsive status epilepticus (SE) in adults and children in Poland. Generalized convulsive $\mathrm{SE}$ is the most common form and also represents the greatest threat to life, highlighting the importance of the choice of appropriate therapeutic treatment.

Aim of guideline: We present the therapeutic options separately for treatment during the early preclinical (>5-30 min), established (30-60 min), and refractory (>60 min) SE phases. This division is based on time and response to AEDs, and indicates a practical approach based on pathophysiological data.

Results: Benzodiazepines (BZD) are the first-line drugs. In cases of ineffective first-line treatment and persistence of the seizure, the use of second-line treatment: phenytoin, valproic acid or phenobarbital is required. SE that persists after the administration of benzodiazepines and phenytoin or another second-line AED at appropriate doses is defined
\end{abstract}

\footnotetext{
* Corresponding author.

E-mail address: kl.neurologii@szpital-orlowskiego.pl (E. Nagańska). https://doi.org/10.1016/j.pjnns.2018.04.002

0028-3843/@ 2018 Polish Neurological Society. Published by Elsevier Sp. z o.o. All rights reserved.
} 
as refractory and drug resistant and requires treatment in the intensive care unit (ICU). EEG monitoring is essential during therapy at this stage. Anesthesia is typically continued for an initial period of $24 \mathrm{~h}$ followed by a slow reversal and is re-established if seizures recur. Anesthesia is usually administered either to the level of the "burst suppression pattern" or to obtain the "EEG suppression" pattern.

Conclusions: Experts agree that close and early cooperation with a neurologist and anesthetist aiming to reduce the risk of pharmacoresistant cases is an extremely important factor in the treatment of patients with SE. This report has educational, practical and organizational aspects, outlining a standard plan for SE management in Poland that will improve therapeutic efficacy.

(c) 2018 Polish Neurological Society. Published by Elsevier Sp. z o.o. All rights reserved.

\section{Introduction}

The Working Group was established at the initiative of the General Board of the Polish Society of Epileptology (PSE) to develop an expert position on the treatment of convulsive status epilepticus (SE) in adults and children in Poland. For many years the PSE has promoted the highest standards of medical care. However, there are few updated papers on management and treatment of SE in Polish literature [1-4].

The development and preparation of these recommendations is a vital contribution for patients with epilepsy in Poland, and now must be translated into daily clinical practice. Physicians, particularly neurologists and neurosurgeons need to be familiar with SE. The generalized convulsive SE is one of the most common life-threatening conditions that requires a prompt rescue therapy in order to prevent from further consequences. Prolonged and/or repetitive tonic-clonic seizures involving a whole body are extremely exhausting and lead to the energy crisis. Besides, the longer the seizure lasts, the lower probability of self-limitation and adequate response to an antiepileptic rescue treatment. All of above factors plus in addition unknown cause of the GTCS (for example a medical origin), lead to the higher morbidity in this emergency situation.

\section{Purpose of this report}

SE treatment should proceed in accordance with familiar and well-understood procedures, but should also be updated and supplemented with new information. Recommendations for SE developed by the European Federation of Neurological Societies (EFNS) as well as the Report of the Guideline Committee of the American Epilepsy Society 2016 have recently been published [5,6], and the new definitions and classifications for SE were developed by the International League Against Epilepsy (ILAE) [7]. Our report has educational, practical and organizational aspects, outlining a standard plan for SE management in Poland that will further improve therapeutic efficacy.

It is also crucial to elaborate a therapeutic treatment protocol for neurologists and anaesthesiologists, ideally available in every neurological and anesthesia ward.

\subsection{Methods}

The expert opinion presented in this paper is based on a review of the current literature regarding strategies for seizure disorder management as well as the clinical experience and good medical practice of clinicians with extensive backgrounds in the area. Each of the panelists provided comments and made remarks, and the version presented here was developed after reaching consensus.

\section{Definitions of terms}

According to Trinka et all 2015 "Status epilepticus is a condition resulting either from the failure of the mechanisms responsible for seizure termination or from the initiation of mechanisms, which lead to abnormally, prolonged seizures (after time point t1). It is a condition, which can have long-term consequences (after time point t2), including neuronal death, neuronal injury, and alteration of neuronal networks, depending on the type and duration of seizures" [7].

Clinical trials suggest that a single seizure seldom lasts longer than $2 \mathrm{~min}$, therefore we assume that the generalized seizures in SE include all cases of seizure lasting $>5 \mathrm{~min}$, or 2 seizures without baseline recovery. This "operational" definition indicates the necessity of immediate pharmacological treatment for all patients with prolonged seizures over $5 \mathrm{~min}$ [5-10]. It should be pointed that in the case of convulsive (tonic-clonic) SE, both time points (t1 at $5 \mathrm{~min}$ and t2 at $30 \mathrm{~min}$ ) are based on animal experiments and clinical research. This evidence is incomplete, and there is furthermore considerable variation, so these time points should be considered as the best estimates currently available [7].

Refractory SE is defined as no response to a benzodiazepine plus an anti-seizure drug [11].

Super-refractory SE is a stage of refractory SE characterized by unresponsiveness to initial anesthetic therapy and is defined as "SE that continues or recurs $24 \mathrm{~h}$ or more after the onset of anesthesia, including those cases in which SE recurs on the reduction or withdrawal of anesthesia." [11]. Super-refractory SE can also be defined as SE that has continued or recurred despite $24 \mathrm{~h}$ of general anesthesia [12].

The new clinical syndrome defined as new-onset refractory status epilepticus (NORSE) refers to patients with acute brain 
injury or patients with no history of epilepsy in whom SE occurs without any apparent cause [5-10], so it still requires the extensive studies to determine the etiology as that increases the odds of a more favorable outcome.

\section{SE epidemiology, etiology and mortality}

In general, SE incidence varies from 9.9 to 41/100,000 per year [12] with a bimodal age distribution. The youngest and oldest patients suffer from SE most often, specifically those in the first decade of life $(14.3 / 100,000)$ and those over 60 years of age $(28.4 / 100,000)$ [13-15]. A significant percentage of patients with SE in both pediatric (16-38\%) and adult populations (42-50\%) have a history of diagnosed epilepsy [16].

Etiology of status epilepticus could be different, namely: cerebrovascular, hemorrhagic stroke, symptomatic, toxic and metabolic, infectious, autoimmunologic, posttraumatic, or non-compliance. Cerebrovascular pathologies are considered to be the basic etiologic factors in adults, especially hemorrhagic stroke (38\%) [17-19].

Reports of mortality related to SE varies. Koubeissi found a prevalence of $3.45 \%$ in a very large population of over 11,500 patients with generalized convulsive SE aged from 13 to 64 years. Short-term mortality over a period of 30 days from the SE episode varied between 7.6 and $22 \%$ in all groups, but was the highest in the oldest group [20,21]. This frequency increased significantly in a subgroup of mechanically ventilated patients. SE prevalence was lower in adults under the age of 60 than in children, but mortality is higher. Mortality rates were $26 \%$ in adults under the age of $60,40 \%$ in patients over 80 , and $5-8 \%$ in children $[16,17]$.

\section{The outcome of the PSE Working Group on the treatment of convulsive SE in adults and children in Poland}

The goal of therapeutic management for SE is to stop the electrographic discharges as quickly as possible, and consequently protect neurons from damage. The diagnostic and therapeutic procedures for children adults are similar, but the medication dosages should be adjusted accordingly.

SE duration prior to starting treatment influences its effect, regardless of the type of medication, and seizure control following pharmacological treatment is inversely related to SE duration prior to treatment.

We present the therapeutic options separately for treatment during the early preclinical ( $>5-30 \mathrm{~min})$, established (30$60 \mathrm{~min}$ ), and refractory (>60 $\mathrm{min}$ ) SE phases. This division is based on time and response to AEDs, and indicates a practical approach based on pathophysiological data.

\section{Management of initial SE (>5-30 min)}

\subsection{Preclinical and first-line treatment}

SE requires immediate and effective treatment $[6,7,22]$. The abnormal discharge of the cortical neurons during convulsive seizure results in the loss of inhibitory synaptic transmission mediators (GABA, glutamate) and pathologically increased neuronal activity. On the other hand, brain trauma, intoxication or infections also increase neuronal excitability and impaired mechanism of seizure termination. In time, the longer the seizure lasts, the natural mechanisms of selflimitation fail and lead to the further neuronal damage. Extremely important is to start rescue therapy and achieve seizure cessation before this pathophysiologic process develops. Therefore, expendable delay in implementation of emergency drugs may result in final ineffectiveness of introduced antiepileptic medication.

Benzodiazepines (BZD) are the first-line drugs, and act as GABA receptor agonists $[7,15,22]$. These drugs are preferred primarily due to the rapid onset of action and high efficacy for controlling seizures [23]. In cases of prolonged convulsive seizure in patients with diagnosed epilepsy, a family member or caregiver may give diazepam by the rectal route before the arrival of emergency services. Many patients with diagnosed epilepsy in Poland and a history of prolonged seizures or previous SE are prescribed diazepam in this form. Diazepam is available in doses of $5 \mathrm{mg}$ and $10 \mathrm{mg}$, and an additional $10 \mathrm{mg}$ per rectal dose may be repeated if seizure persists. In children, $5 \mathrm{mg}$ ( $>10 \mathrm{~kg}$, age $1-3$ years) or $10 \mathrm{mg}$ ( $>15 \mathrm{~kg}$, age $>3$ years) is recommended, depending on age and body weight. This dose can be repeated if necessary, at $5 \mathrm{mg}$ in younger children and $10 \mathrm{mg}$ in older children. Administration of the drug to very young children ( $<1$ or over $<10 \mathrm{~kg}$ ) is not recommended by the manufacturer.

Midazolam is marketed under the trade name Buccolam and available in the form of pre-filled oral syringes, the solution is absorbed through the mucosa of the inner side of the cheek. Midazolam used at a dose of $0.5 \mathrm{mg} / \mathrm{kg}$ is as effective and safe as rectally administered diazepam, and is easier to use with a shorter half-life. There are also intranasal forms of midazolam, which are administered at a dose of $0.2 \mathrm{mg} / \mathrm{kg}$ and also have greater efficacy and safety than rectal diazepam. The preparation is registered in Poland for use in children from 3 months to 18 years of age only, but it is not currently produced in Poland and must be imported.

The rectal form of diazepam, nasal form of midazolam, or buccal midazolam can be used as alternative initial therapies (level B) in prehospital settings. The initial therapy should be administered as a single full dose, rather than small multiple doses, and should not be administered twice with the exception of IV lorazepam and diazepam (one-time repeat of the full dose) (level A, 2 class I tests, one class II RCT). There was no significant difference in efficacy between IV lorazepam and IV diazepam in children with SE (level A). Midazolam (IM/ nasal/buccal) is probably more effective than diazepam (IV/ rectal, level B) for children [6,28-30].

\subsection{Emergency service and pharmacological treatment}

After reaching the patient during prolonged tonic-clonic seizure or SE, the task of emergency services is to either obtain information from the witnesses regarding the seizure or to estimate the duration, potential cause, accompanying diseases including epilepsy, circumstances of the seizure, provocative factors, medications or missed doses, exposure to 


\section{Table 1 - General support/monitoring of SE.}

All drugs should be administered intravenously (IV) by two-way procedure:

- Introduction of a cannula into a vein to collect blood for diagnostic testing for the causes of SE including biochemical testing and AED level determination.

- Introduction of a second cannula into the vein for AED administration. The injection should be maintained by administering saline solution, and glucose solution should not be administered because of the possibility of AED precipitation, especially when using phenytoin. - Vital function monitoring, stabilization of respiratory and circulatory functions, and blood pressure control. Glucose should be administered only in cases of documented hypoglycemia in a bolus of $50 \mathrm{ml} 50 \%$ glucose for adults and $2 \mathrm{ml} / \mathrm{kg} 25 \%$ glucose for children. It is worth noting that hyperglycemia may exacerbate neuronal damage. $100 \mathrm{mg}$ of thiamine can be given IV for chronic alcoholics or addicts before or simultaneously with the administered glucose

- Body cooling if the temperature is high.

toxic and intoxicating substances including alcohol, risk of aspiration, and potential injuries that precede or result from the seizure itself.

At the same time, the requirements include the urgent need to estimate airway patency and cardiorespiratory efficiency including the assessment of saturation, heart rate, blood pressure, and ECG, and implementation of oxygen therapy. Adequate ventilation is maintained in most patients with SE, provided that the airways are not obstructed. The insertion of an oropharyngeal tube and administration of oxygen through a nasal mustache or ventilation with the Ambu bag typically provide adequate oxygenation, and intravenous access is recommended (Table 1).

Immediate first line treatment should be introduced simultaneously. Benzodiazepines are the first line treatment for SE, the following are available in Poland (Table 2):

(a) Diazepam: intravenously (IV) administered slowly at a dose of $10-20 \mathrm{mg}$ in adults (the dose may be repeated) or $0.2-0.3 \mathrm{mg} / \mathrm{kg}$ in children (or $1 \mathrm{mg}$ for each year of life), administered slowly at $2-5 \mathrm{mg} / \mathrm{min}$. It reaches the appropriate concentration in the CNS after approximately $1 \mathrm{~min}$ by IV administration, and the maximum concentration occurs within $15 \mathrm{~min}$ of dosing. It is metabolized in the liver to the active metabolites oxazepam, temazepam, and demethyldiazepam, which prolongs the duration. The half-life of diazepam is approximately $48 \mathrm{~h}$ [23-26].

(b) Clonazepam: IV administered in a single dose of $1 \mathrm{mg}$ in adults and $0.5 \mathrm{mg}$ in children. The speed of IV injection in adults should not exceed $0.25-0.5 \mathrm{mg}$ per minute. It should be noted that this drug has not been included in the current international guidelines for the treatment of SE, however in our experience it is efficacious and widely available in Poland.

\section{Table 2 - First line treatment.}

\begin{tabular}{ll} 
Drug & \multicolumn{1}{c}{ Dosage } \\
\hline Diazepam & $\begin{array}{l}\text { Iv } 10-20 \mathrm{mg} \text { in adults, 02, 03 mg/kg in } \\
\text { children }\end{array}$ \\
Clonazepam & Iv $1 \mathrm{mg}$ in adults, $0.5 \mathrm{mg}$ in children \\
Lorazepam & Iv $0.05-0.1 \mathrm{mg} / \mathrm{kg}$ \\
Midazolam & Iv $2.5 \mathrm{mg}<1$ year, $5 \mathrm{mg}, 1-5$ years old, \\
& $7.5 \mathrm{mg}, 5-10$ years, $10 \mathrm{mg}$ in $10-18$ and \\
& adults \\
& Im $0.2 \mathrm{mg} / \mathrm{kg}$ \\
\hline
\end{tabular}

(c) Lorazepam: commonly used in the USA and in many European countries. The recommended IV dosage of is $0.05-0.1 \mathrm{mg} / \mathrm{kg}$ (typically $4-8 \mathrm{mg}$ ) for $2-5 \mathrm{~min}$. If the seizure persists after $10 \mathrm{~min}$, another $4 \mathrm{mg}$ IV is recommended $[5,6,25,26]$. The IV form of lorazepam is not registered in Poland.

(d) Midazolam is administered to control SE, and is available for either IV administration or IM injection. IV dosage age $2.5 \mathrm{mg}$ for children $<1$ year old, $5 \mathrm{mg}$ for children $1-5$ years old, $7.5 \mathrm{mg}$ for children from 5 to 10 years, and $10 \mathrm{mg}$ for children aged $10-18$ years and older patients $(0.1-0.2 \mathrm{mg} / \mathrm{kg}$ IV) or $0.2 \mathrm{mg} / \mathrm{kg}$ IM $[25,27]$.

According to the Report of the Guideline Committee of the American Epilepsy Society (2016), IM midazolam, IV lorazepam, or IV diazepam are recommended as the initial therapies of choice, based on demonstrated efficacy, safety, and tolerability (level 1, 4 studies of class I RCTs). IV phenobarbital may be an alternative initial therapy, but is not the first choice drug (level A, one class I RCT test) [6].

Adverse effects of benzodiazepines such as sedation and respiratory depression up to apnea, especially if the drug is administered too quickly or if the dosage is exceeded [15]. Therefore, it is extremely important to determine whether caregivers administered benzodiazepines earlier and whether the patient took benzodiazepines in oral form before the onset of the prolonged seizure. IV benzodiazepines should be administered in a slow infusion and the patient should be closely monitored during parenteral administration. The availability of the resuscitation kit should be always verified $[5,7,14,15]$, and it should be emphasized that if it is not possible to determine the time of SE onset in a patient who has not been previously treated, the patient should receive first-line treatment.

Patients should be transported to the nearest Emergency Department in hospital with a neurological ward.

Expert opinion suggests the necessity of increasing the availability of lorazepam in Poland, which penetrates vascular tissues more slowly, and has a longer therapeutic effect and a lower risk of accumulation in organs (lesser risk of cardiovascular depression).

\section{Management of established SE (30-60 min)}

\subsection{Second-line treatment}

Established SE is diagnosed in cases of ineffective first-line treatment and persistence of the seizure, requiring the use of 
Table 3 - Second line treatment.
Drug

Phenytoin

Valproic acid

Phenobarbital

Chloral hydrate
Dosage

Iv infusion $20 \mathrm{mg} / \mathrm{kg}$ (max rate $25 \mathrm{mg} / \mathrm{min}$ ) Iv $20-40 \mathrm{mg} / \mathrm{kg}$ (max rate $6 \mathrm{mg} / \mathrm{kg} / \mathrm{min}$ ) Iv $20 \mathrm{mg} / \mathrm{kg}$ (max rate $50 \mathrm{mg} / \mathrm{min}$ ) Pr $0.3-0.5 \mathrm{ml} / \mathrm{kg}$ second-line treatment. This typically occurs in a hospital setting.

These medications are recommended for second-line SE treatment (Table 3):

(a) Phenytoin: is a well-known and widely accessible antiepileptic drug. It's mechanism of action is inhibition of sodium channels. By working on intracellular part of the ion channel it decreases the inflow of sodium into the cell, which result in reduction of excitability of cortical neurons. Stabilizes the cell membrane of central neurons. Phenytoin is insoluble in water and requires an alkaline solvent to prevent from precipitation. This alkalinity is responsible for rather mild adverse events, such as skin irritation, thrombophlebitis or local tissue necrosis. Purple glove syndrome (triad of edema, discolouration and pain distally to injection site) is uncommon and mild. However, phenytoin increases a risk of cardiac arrhythmias as well as hypotension. Therapeutic level ranges vary between 10 and $20 \mu \mathrm{g} / \mathrm{ml}$. Overdose is manifested by horizontal nystagmus. Phenytoin is perfectly suited for quick seizure control as well as chronic therapy $[24,25,31]$, reaches maximum concentration in the cerebrospinal fluid after $20 \mathrm{~min}$, and has a half-life is $24 \mathrm{~h}$ which may be prolonged by high concentrations of phenytoin in the blood. The concentration in brain tissue is 3-4 times higher than in blood and lasts for several hours. Phenytoin is administered in an infusion pump as an continuous intravenous infusion of $20 \mathrm{mg} / \mathrm{kg}$ (at a maximum rate of $25 \mathrm{mg} / \mathrm{min}$ ). Administration should begin quickly and the flow should be adjusted in order to stop the seizures. It should then be brought to a daily dose that will provide the therapeutic concentration of the drug in the blood serum, this typically takes a few days and the daily dose of $2000 \mathrm{mg} / 24 \mathrm{~h}$ should not be exceeded. The drug can then be administered orally $[15,23,24,32]$. The benefits of phenytoin include the longlasting effects, rapid achievement of high-level concentration in the cerebrospinal fluid, wide availability, and many years of experience associated with its application.

(b) Phenytoin should not be administered in a glucose solution due to the precipitation of microcrystals. Blood pressure and ECG should be monitored during phenytoin treatment, and patients with impaired renal and hepatic function should have the phenytoin-free fraction monitored. Cardiovascular system monitoring is necessary due to the possibility of hypotension (27\%) and bradyarrhythmia (7\%). Other side effects of phenytoin include "purple glove syndrome" characterized by edema, discoloration, and pain distal to the injection site, as well as the possibility of inducing sterile abscesses at the injection site. There is little data confirming safe use of phenytoin in the elderly population (due to the possible negative impact of phenytoin on the cardiovascular system and sometimes undesirable neuroprotective effect of the drug). Phenytoin may be substituted by fosphenytoin, a phenytoin prodrug, administered by IV or IM. Although fosphenytoin has fewer adverse effects than phenytoin, particularly a reduced risk of local irritation, it is not currently available or used in Poland [15,32,33]. IV valproic acid (VPA) at a dose of 20 $40 \mathrm{mg} / \mathrm{kg}$ may also be used at a speed of $6 \mathrm{mg} / \mathrm{kg} / \mathrm{min}$. The results of more than 20 published studies (both retrospective and prospective) in children and adults including over 500 patients suggest that VPA is as effective as phenytoin for the treatment of SE that cannot be controlled by benzodiazepines. This data can be found in the Report of the Guideline Committee of the American Epilepsy Society (level B, one study class II) [6]. Valproate does not induce hypotension, respiratory depression, or severe sedation. Intravenous valproate is considered to be a therapeutic option especially in patients with cardiovascular diseases. Although the precise mechanism of action is not known, several mechanisms have been suggested. VPA may potentiate postsynaptic GABA, inhibit GABA-transaminase and succinic acid decarboxylase, and/or increase glutamic acid decarboxylase. It may also block voltage-gated sodium channels to limit depolarization-induced, sustained repetitive firing and may block low-threshold T-type calcium channels. Many consensus guidelines recommend the use of VPA as an alternative second-line treatment. Reports on SE unresponsive to first-line agents have generally noted successful termination of seizures following intravenous VPA. If given in large doses and by rapid infusion, VPA rarely causes cardiovascular toxicity such as hypotension or arrhythmia. However, VPA can cause coagulopathies such as platelet dysfunction, thrombocytopenia, and hypofibrinogenemia. Although rare, pancreatitis or DRESS syndrome has been noted after VPA. Important to note is that VPA is a cytochrome P450 inhibitor, thus interacts with many other medications, similar to phenytoin. This agent is particularly problematic in patients with inborn errors of metabolism, such as ornithine carbamyltransferase deficiency. Valproic acid is administered as $20-40 \mathrm{mg} /$ $\mathrm{kg}$ IV over $10 \mathrm{~min}$, and an additional $20 \mathrm{mg} / \mathrm{kg}$ can be given if the patient is still seizing. The goal blood level is $100 \mu \mathrm{g} /$ $\mathrm{mL}$, and can be drawn immediately after the loading dose has been administered. Maximum dose of $3 \mathrm{~g}$. [34]

(c) Phenobarbital: administered at a rate of $20 \mathrm{mg} / \mathrm{kg}$, with a maximum speed of administration up to $50 \mathrm{mg} / \mathrm{min}$. Phenobarbital has historically been used for benzodiazepine-resistant SE. According to the Report of the Guideline Committee of the American Epileptic Society, IV phenobarbital is treated as an alternative therapy due to side effects (level B, one class II test). There are also reports indicating that up to $20 \%$ of patients who have clinically resolved symptoms of SE after applying phenobarbital have persistent electrographic features of $\mathrm{SE}[5,7,35]$. Phenobarbital binds to inhibitory GABA-A receptors. It leads to the increased duration of the chloride channels opening. It also inhibits sodium and calcium channels at the AMPA receptor to reduce the release of glutamate. Therapeutic dose should range from 20 to $30 \mathrm{mg} / \mathrm{kg}$. In medical trials the efficacy of phenobarbital proves to be 
higher than phenytoin (65-58\% respectedly). It is quite cheap and the efficacy in seizure cessation is fairly enough in established generalized convulsive SE. However, it is a cytochrome $\mathrm{P} 450$ inducer, therefore it interacts with many medications and has a worse side effect profile, with a propensity to cause hypotension, sedation, and respiratory depression, particularly during rapid infusion. Phenobarbital should be given as a bolus of $10-20 \mathrm{mg} / \mathrm{kg}$ IV at a rate of $50-100 \mathrm{mg} / \mathrm{min}$, up to a total amount of $700 \mathrm{mg}$ in about seven min. Patients must have their respiration and blood pressure monitored while they are receiving the bolus [34].

(d) Chloral hydrate is another older drug that could be considered, especially in situations with no intravenous option. It is applicated per rectum, in a dose of $0.3-0.5 \mathrm{ml} /$ $\mathrm{kg}$ dissolved 1:1 in vegetable oil, and can be repeated after $20 \mathrm{~min}$ [34].

Specific treatments for brain edema (e.g. mannitol or steroids) are indicated in select cases only, depending on the patient's clinical condition. Use of these treatments requires a careful assessment of potential contraindications.

Experts agree that the treatment of established SE should be performed in the neurological ward.

\section{Management of refractory SE (>60 min)}

SE that persists after the administration of benzodiazepines and phenytoin or another second-line AED at appropriate doses is defined as refractory and drug resistant and requires treatment in the intensive care unit (ICU). EEG monitoring is essential during therapy at this stage [5,7].

The optimal anesthetics for use in pharmacological coma are still unknown. The drugs most commonly used for this purpose include pentobarbital, thiopental, propofol, and midazolam, which appear to have similar efficacies as reported in the literature $[5,7,26,27]$ (Table 4). The choice of anesthesia depends largely on side effect considerations [36]. Propofol is the easiest anesthetic to use from a pharmacokinetic and pharmacologic point of view, and pentobarbital and thiopental are the most difficult. Propofol carries a particular risk of propofol infusion syndrome characterized by: hypotension, bradyarhythmias, heart failure, hyperkalemia, hepatomegaly, lipemia, metabolic acidosis, and rhabdomyolysis $[34,36]$ and midazolam is associated with a particular risk of

Table 4 - Dosage of anesthetics for SE treatment.

\begin{tabular}{ll} 
Drug & \multicolumn{1}{c}{ Dosage } \\
\hline Thiopental & $-3-5 \mathrm{mg} / \mathrm{kg}$ IV bolus, additional doses \\
& $1-2 \mathrm{mg} / \mathrm{kg}$, repeated every $2-3 \mathrm{~min}$ until \\
& seizures controlled \\
& - maintenance at $3-7 \mathrm{mg} / \mathrm{kg} / \mathrm{min}$ \\
Pentobarbital & $-10-15 \mathrm{mg} / \mathrm{kg}$ IV bolus \\
& - maintenance at $0.5-1 \mathrm{mg} / \mathrm{kg} / \mathrm{h}$ \\
Midazolam & $-0.2 \mathrm{mg} / \mathrm{kg}$ IV bolus \\
& - maintenance at $0.05-0.4 \mathrm{mg} / \mathrm{kg} / \mathrm{h}$ \\
Propofol & $-2-3 \mathrm{mg} / \mathrm{kg}$ IV bolus, additional doses \\
& $1-2 \mathrm{mg} / \mathrm{kg}$ repeated until seizures \\
& controlled \\
& - maintenance at 2-10 $\mathrm{mg} / \mathrm{kg} / \mathrm{h}$ \\
\hline
\end{tabular}

acute tolerance. All three anesthetics carry the serious side effects of hypotension and cardiac depression.

Anesthesia is typically continued for an initial period of $24 \mathrm{~h}$ followed by a slow reversal. Anesthesia is re-established if seizures recur. Aesthesia is usually administered either to the level of the "burst suppression pattern" or to obtain the "EEG suppression" pattern, however, complete suppression of EEG activity is associated with a higher risk of hypotension and there is no data demonstrating an association with lower mortality, therefore this is an arbitrary decision [11].

Measuring serum AED levels may be useful for optimizing further treatment in patients with epilepsy, but therapeutic decisions focus primarily on the patient's clinical condition.

Intravenous administration of phenytoin or valproate should be continued during withdrawal from a barbiturate coma to prevent recurrence.

Second-line therapy is usually less effective (adult-level A, one class I RCT test, children-level C, two class III RCTs), and third-line therapy is significantly less effective (adults-level A, one RCT class I test, children-level U) than initial therapy. Therefore repeating the second-line treatment with another drug or anesthetic route (thiopental, midazolam, pentobarbital, or propofol, all with monitored continuous EEG activity)) should be considered when second-line therapy is ineffective. Patients can be transferred faster from phase to phase and a phase can be omitted for patients requiring ICU treatment, depending on seizure etiology and severity $[5,7,26,27]$.

Under no circumstances should antiepileptic treatment be stopped in patients previously treated for epilepsy.

\section{Management of super-refractory SE}

Super refractory status epilepticus is defined as "SE that continues or recurs $24 \mathrm{~h}$ or more after the onset of anesthesia, including cases in which SE recurs after the reduction or withdrawl of anesthesia" [11]. Therapy includes alternative third-line treatment, and is therefore similar to the management of refractory epilepsy [27]. Other nonpharmacological treatments include vagus nerve stimulation or surgery such as the removal of the epileptic focus, hemispherectomy, and callosotomy [37-39]. It is typical to continue anesthesia for an initial period of $24 \mathrm{~h}$ and followed by a slow reversal. Anesthesia is reestablished if seizures recur. This pattern of instituting and withdrawing anesthesia is initially continued in 24-48 h cycles and then at 5-7 day cycles [11].

In addition to anesthesia, a wide range of antiepileptic drugs including levetiracetam topiramate, oxcarbazepine, and lacozamide have been used in patients with super-refractory SE. Whether any is superior is unclear, and it is likely that no drug has a strikingly different efficacy than any other. However it is important to consider a combination of two or three antiepileptic drugs at high doses, without switching too often. These drugs can be administered at high doses without a significant risk of idiosyncratic reactions [40-45].

Experts agree that new AEDs should be included in the SE treatment guidelines, due to the increasing number of reports of AED treatment indicating the efficacy and safety of LEV, TPM, OCBZ, and LCM for the treatment of resistant SE [5,6,11,22,38-40]. 
None of these drugs are currently registered in Poland for this indication.

\subsection{Alternative therapeutic options}

Immunomodulatory treatments such as steroids, intravenous immunoglobulins, and plasma replacement are also used in patients with refractory SE, sometimes for patients who do not have clear evidence of inflammatory etiology. It is important to stress that some cases of NORSE remain undiagnosed, are presumed to be due autoimmune etiology and in these group of patients early initiation of immunotherapy could be beneficial. For steroid therapy, tests are conducted using IV methylprednisolone at a dose of $1 \mathrm{~g}$ for 3 days, and then $1 \mathrm{mg} /$ $\mathrm{kg}$ is continued for approximately 6 weeks. Immunoglobulins are administered at a dose of $0.4 \mathrm{mg} / \mathrm{kg}$ for 5 days, and the treatment is repeated twice at a 2 weeks interval. Reports are currently limited to a small group of patients, therefore there are no standardized recommendations for the use of immunological therapy $[15,27,46]$.

(a) Ketamine is an anesthetic frequently described as a potentially useful therapy, although there are few published reports [47]. It has two advantages over the conventional anesthetics. First, it has no cardiac depressant properties and does not cause hypotension, and it is potentially neuroprotective because it is a strong $\mathrm{N}$ methyl-D-aspartate (NMDA) antagonist, although glutaminergic damage may already have occurred by the time it is employed. During prolonged seizures, the numbers and activities of GABA receptors gradually decrease; thus, the commonly used first-line and second-line antiepileptic drugs become less effective in long term. Simultaneously, the numbers and activities of glutamatergic NMDA receptors increase, often causing refractory status epilepticus and thus providing the possibility of beneficial use of ketamine to treat SE. Lidocaine and inhaled anesthetics (isoflurane) can also be efficacious in some cases of refractory SE, however there are no well-defined criteria to determine when they should be used or their optimal dosing schedule.

(b) Isoflurane is administered at $0.8-2$ vol\%, titrated to obtain the EEG "suppression burst" pattern. Isoflurane may induce hypotension, atelectasia, paralytic ileus and deep venous thrombosis.

(c) Lidocaine is administered as a $1.5-2 \mathrm{mg} / \mathrm{kg}$ as i.v. bolus (commonly $100 \mathrm{mg}$ in adults), at a maximum rate of $50 \mathrm{mg}$ / min. A second bolus can be administered if needed. Lidocaine may induce hypotonia, hallucinations, and bradyarrhythmias, These drugs should only be administered by experienced physicians [15,22,27,47-49].

(d) Ketogenic diet for epilepsy has been used for many decades, especially for children. It is occasionally recommended for people with refractory SE. The effects of a ketogenic diet treatment can begin after several days or even weeks $[26,46]$. However, caveat for ketogenic diet it requires in many cases a nutritionist as these patients are often intubated. Furthermore, it requires pharmacist involvement as many IV drug solutions or IV fluids contain dextrose, which must be eliminated to achieve ketosis. (e) Hypothermia is carried out in adults by intravascular cooling and in children by external cooling to 32-35 degrees Celsius. It should be emphasized that these reports are all of a casuistic nature $[27,50]$.

\section{Conclusions}

Experts agree that close and early cooperation with a neurologist and anesthetist aiming to reduce the risk of pharmacoresistant cases is an extremely important factor in the treatment of patients with SE.

The verification of the diagnosis at each stage of therapy is also critically important. The goal of treatment is not only to relieve the clinical and electrographic features of SE, but also to prevent the recurrence of epileptic seizures and treat postepileptic complications as well as the complications associated with the treatments used.

Experts emphasize that a lack of effectiveness could be related to a number of factors, such as insufficient drug doses, irregular administration, suspension of aggressive treatment, or early discontinuation of therapy. We hope that these recommendations at the current stage of theoretical knowledge and experience will guide treatment to the most optimal form for taming generalized tonic-clonic SE as quickly as possible. These recommendations aim to help clinicians understand the relevant existing evidence for treatment of patients with status epilepticus and are intended for use by individual clinicians, hospitals, health authorities, and providers in Poland.

\section{Conflict of interest}

None declared.

\section{Acknowledgement and financial support}

None declared.

\section{R E F E R E N C E S}

[1] Jędrzejczak J. Objawy kliniczne i postępowanie w stanie padaczkowym. Przew Lek 2003;6:72-6.

[2] Mazurkiewicz-Bełdzińska M, Szmuda M, Zawadzka M, Matheisel A. Współczesne leczenie drgawkowego stanu padaczkowego - algorytm leczenia i przegląd piśmiennictwa. Anestezjologia Intensywna Terapia 2014;46:309-17.

[3] Rejdak K. Współczesne algorytmy diagnostyczne i standardy terapeutyczne w nowo rozpoznanej padaczce u dorosłych. Polski Przegląd Neurologiczny 2010;3:131-3.

[4] Szklener S, Godek M, Korchut A, Balicka-Adamik L, Rejdak R, Rossetti AO, et al. Outcome prediction in patients with acute repetitive seizures: application of the Status Epilepticus Severity Score. Epilepsia 2018;59(May (5)):e68-72.

[5] Meierkord H, Boon P, Gocke K, Shorvon S, Tinuper S, Holtkamp M. EFNS guidelines on the management of status epilepticus in adults. Eur J Neur 2010;17:348-55. 
[6] Glauser T, Shinnar S, Gloss D, Alldredge B, Arya R, Bainbridge J, et al. Evidence-based guideline: treatment of convulsive status epilepticus in children and adults: Report of the Guideline Committee of the American Epilepsy Society. Epilepsy Curr 2016;16:48-61.

[7] Trinka E, Cock H, Hesdorffer D. A definition and classification of SE - report of the ILAE task force on classification of status epilepticus. Epilepsia 2015;56:151523.

[8] Commission on classification and terminology of the International League Against Epilepsy: proposal for revised clinical and electroencephalograpihic classification of epileptic seizures. Epilepsia 1981;22:489-501.

[9] Jenssen S, Gracely E, Sperling M. How long do most seizures last? A systematic comparison of seizures recorded in the epilepsy monitoring unit. Epilepsia 2006;47:1499-503.

[10] Lowenstein D, Bleck T, Macdonald R. It's time to revise the definition of status epilepticus. Epilepsia 1999;40:120-2.

[11] Shorvon S. Super-refractory status epilepticus: an approach to therapy in this difficult clinical situation. Epilepsia 2011;52:53-6.

[12] Shorvon SD, Ferlisi M. The treatment of super-refractory status epilepticus: a critical review of available therapies and a clinical treatment protocol. Brain 2011;134:2802-18.

[13] Sanchez S, Rincon F. Status epilepticus: epidemiology and public health needs. J Clin Med 2016;5(8). http://dx.doi.org/ 10.3390/jcm5080071

[14] Millikan D, Rice B, Silbergleit R. Emergency treatment of status epilepticus: current thinking. Emerg Med Clin North Am 2009;27:101-13.

[15] Rossetti A. Treatment options in the management of status epilepticus. Curr Treat Options Neurol 2010;12:100-12.

[16] Novy J, Logroscino G, Rosetti A. Refractory status epilepticus: a prospective observational study. Epilepsia 2010;51:251-6. http://dx.doi.org/10.1111/j.1528-1167.2009. 02323.x

[17] Raspall-Chaure M, Chin R, Neville B, Bedford H, Scott RC. The epidemiology of convulsive status epilepticus in children: a critical review. Epilepsia 2007;48:1652-63.

[18] DeLorenzo RJ, Kirmani B, Deshpande LS, Jakkampudi V, Towne AR, Waterhouse E, et al. Comparisons of the mortality and clinical presentations of status epilepticus in private practice community and university hospital settings in Richmond, Virginia. Seizure 2009;18(July (6)):40511. http://dx.doi.org/10.1016/j.seizure.2009.02.005

[19] Shearer P, Riviello J. Generalised convulsive status epilepticus in adults and children: treatment guidelines and protocols. Emerg Med Clin North Am 2011;29:51-64.

[20] Koubeissi M, Alshekhlee A. In-hospital mortality of generalized convulsive status epilepticus - a large US sample. Neurology 2007;69:886-93.

[21] Wylie T, Murr N. Status epilepticus. StatPearls. Treasure Island, FL: StatPearls Publishing; 2017, February.

[22] Brophy G, Bell R, Claassen J, Alldredge B, Bleck TP, Glauser $\mathrm{T}$, et al. Guidelines for the evaluation and management of status epilepticus. Neurocrit Care 2012;17:3-23.

[23] Rajshekher G. Recent trends in the management of status epilepticus. Indian J Crit Care Med 2005;9:52-63.

[24] Browne $T$. The pharmacokinetics of agents used to treat status epilepticus. Neurol 1990;40:28-32.

[25] Turner C. The management of tonic-clonic status epilepticus. Curr Anaesth Crit Care 2007;18:86-93.

[26] Chen J, Wasterlain C. Status epilepticus: pathophysiology and management in adults. Lancet Neurol 2006;5:246-56.

[27] Shorvon S, Ferlisi M. The outcome of therapies in refractory and super-refractory convulsive status epilepticus and recommendations for therapy. Brain 2012;135:2314-28.
[28] Alldredge B, Wall D, Ferriero D. Effect of prehospital treatment on the outcome of status epilepticus in children. Pediatr Neurol 1995;12:213-6.

[29] Hirsch L. Intramuscular versus intravenous benzodiazepines for prehospital treatment of status epilepticus. New Engl J Med 2012;7:659-60.

[30] Lowenstein D, Alldredge B, Allen F, Neuhaus J, Corry M, Gottwald M, et al. The prehospital treatment of status epilepticus (PHTSE) study: design and methodology. Control Clin Trials 2001;22:290-309.

[31] Martland T, Harris C. Management of status epilepticus. Paediatr Child Health 2009;19:225-31.

[32] Treiman D, Meyers P, Walton N. A comparison of four treatments for generalized convulsive status epilepticus. Veterans affairs status epilepticus cooperative study group. New Engl J Med 1998;339:792-8.

[33] Popławska M, Borowicz KK, Czuczwar SJ. The safety and efficacy of fosphenytoin for the treatment of status epilepticus. Expert Rev Neurother 2015;15:983-92.

[34] Trinka E, Höfler J, Leitinger M, Brigo F. Pharmacotherapy for status epilepticus. Drugs 2015;75:1499-521.

[35] Shorvon S. Status epilepticus: its clinical features and treatment in children and adults. Cambridge: Cambridge University Press; 1994.

[36] Lyer V, Hoel R, Rabinstein A. Propofol infusion syndrome in patients with refractory status epilepticus: an 11-year clinical experience. Crit Care Med 2009;37:3024-30.

[37] De Herdt V, Waterschoot I, Vonck K. Vagus nerve stimulation for refractory status epilepticus. Eur J Paediatr Neurol 2009;13:286-9.

[38] Lhatoo S, Alexopoulos A. The surgical treatment of status epilepticus. Epilepsia 2007;48(Supply 8):61-5.

[39] Bhatia S, Ahmad F, Miller I, Ragheb J, Morrison G, Jayakar P, et al. Surgical treatment of refractory status epilepticus in children. J Neurosurg Pediatr 2013;12:360-6.

[40] Yasiry Z, Shorvon S. The relative effectiveness of five antiepileptic drugs in treatment of benzodiazepineresistant convulsive status epilepticus: a meta-analysis of published studies. Seizure 2014;33:167-74.

[41] Knake S, Gruener J, Hattemer K. Intravenous levetiracetam in the treatment of benzodiazepine refractory status epilepticus. J Neurol Neurosurg Psychiatry 2008;79:588-9.

[42] Ruegg S, Naegelin Y, Hardmeier M. Intravenous levetiracetam: treatment experience with the first 50 critically ill patients. Epilepsy Behav 2008;12:477-80.

[43] Towne A, Garnett L, Waterhouse E, Morton LD, DeLorenzo RJ. The use of topiramate in refractory status epilepticus. Neurol 2003;60:332-4

[44] Kellinghaus C, Berning S, Stogbauer F. Use of oxcarbazepine for treatment of refractory status epilepticus. Seizure 2014;23:151-4.

[45] Robakis T, Hirsch L. Literature review, case report and expert discussion of prolonged refractory status epilepticus. Neurocrit Care 2006;4:35-46.

[46] Walker D, Teach S. Update on the acute management of status epilepticus in children. Curr Opin Pediatr 2006;18:239-44.

[47] Pruss H, Holtkamp M. Ketamine successfully terminates malignant. Epilepsy Res 2008;62:1428-31.

[48] Mirsattari S, Sharpe M, Young G. Treatment of refractory status epilepticus with inhalational anesthetic agents isoflurane and desflurane. Arch Neurol 2004;60:1254-9.

[49] Iannetti P, Spalice A, Parisi P. Calcium channel blocker verapamil administration in prolonged and refractory status epilepticus. Epilepsia 2005;46:967-9.

[50] Corry J, Dhar R, Murphy T, Diringer M. Hypothermia for refractory status epilepticus. Neurocrit Care 2008;9:189-97. 